\title{
Effect of Chemical Extraction on Physicochemical and Mechanical Properties of Doum Palm Fibres
}

\author{
S. Zannen, L. Ghali, M. T. Halimi, M. Ben Hssen \\ Textile Engineering Laboratory, University of Monatir, Monatir, Tunisia \\ Email: saoussenzannen@yahoo.fr
}

Received 10 August 2014; revised 27 September 2014; accepted 13 October 2014

Copyright (C) 2014 by authors and Scientific Research Publishing Inc.

This work is licensed under the Creative Commons Attribution International License (CC BY). http://creativecommons.org/licenses/by/4.0/

(c) (i) Open Access

\section{Abstract}

The aim of this study is to investigate the effect of chemical extraction method on the properties of doum palm fibres. The method of extraction which is carried out is a soda treatment. First, an investigation of the extraction processes was undertaken. Secondly, the physical properties (surface morphology, density, linear density and diameter), the mechanical properties (tenacity, strain) and chemical properties (FT-IR spectra) of doum palm fibres were inspected. Finally, a comparison between properties of doum palm fibres and other vegetal ones has been included. Results indicates an influence of soda treatment on properties of Doum palm fibers. In fact, there is an improvement on fibers diameter and linear density while increasing soda concentration, temperature and treatment duration. Moreover, the studied fibers have a low density which does not exceed 1. The fibers tenacity achieved the maximum value of $20.86 \mathrm{cN} / \mathrm{Tex}$ when precessing in the following combination $\left(0.75 \mathrm{~N}, 100^{\circ} \mathrm{C}\right.$ and $\left.180 \mathrm{mn}\right)$. In the end, the FTIR spectra reveals a change in structure after this alkali treatment while increasing the cellulose amount exposed on the fiber surface and consequently the number of possible reaction sites $(\mathrm{OH}$ groups).

\section{Keywords}

Doum Palm Fibres, Leaf Sheath, Extraction, Soda Treatment, Physical Properties, Mechanical Properties, Chemical Properties

\section{Introduction}

Environmental constraints and new regulations on the recycling of the composites materials have led manufacturers to develop new materials from renewable resources such as natural fibers [1]. The introduction of these 
fibers in polymer matrix can provide significant advantages compared to traditional fibers used in composites such as glass fibers: low density, good mechanical properties, biodegradability and low cost. The number of studies on these new materials is continually increasing and their development is an important issue.

Knowledge of the properties and characteristics of natural vegetable fibers is essential to prevent the effect of fibers structure properties on those of composite materials. Vegetable fiber is one of the varieties of natural fibers obtained from stems, leaves, roots, fruits and seeds of plants. All the ligno-cellulosic based natural fibers consist of cellulose micro-fibrils in an amorphous matrix of lignin and hemi-cellulose [2].

The notion of variability in fiber is important and should be taken into account in the case of these fibers (vegetable fibers). The botanical origin, maturity and method of extraction involve variations of dimensional and structural properties of the fibers (density, diameter, linear density, resistance, morphological structure, etc.) [3] [4].

Different types of vegetable fibers have become widely used as reinforcement in composite materials such as flax [5], jute [6], hemp [7], coir [8], etc. Other fibers such as palm fiber have not yet exploited on an industrial scale.

The aim of this research is to investigate the extraction procedures for palm fibers and to highlight the effect of the procedure extraction on their properties. These fibers are collected from the palm termed "doum palm". It has been chosen in this study, thanks to their abundance and the high diversity of palm trees in Tunisia.

\section{Materials and Methods}

\section{A. Materials}

Investigated fibers are collected from Tunisian Doum palm tree. This biomass was chosen due to their abundance in the roads and the green spaces of Tunisia as an ornament tree.

The source of these fibers is the foliage of the palm tree in particular from the leaf sheath. The leaf sheath is a part of the leaf of the tree. Indeed, the leaf is divided into several parts: the blade and the leaf axis, the latter is itself divided into a sheath encircling the stem, leafstalk and rachis bearing leaflets [9] as showing in the Figure 1.

Leaf sheaths (Figure 2) being arranged one above the other along the trunk of the palm. They are obtained after the trimming of the palm tree.

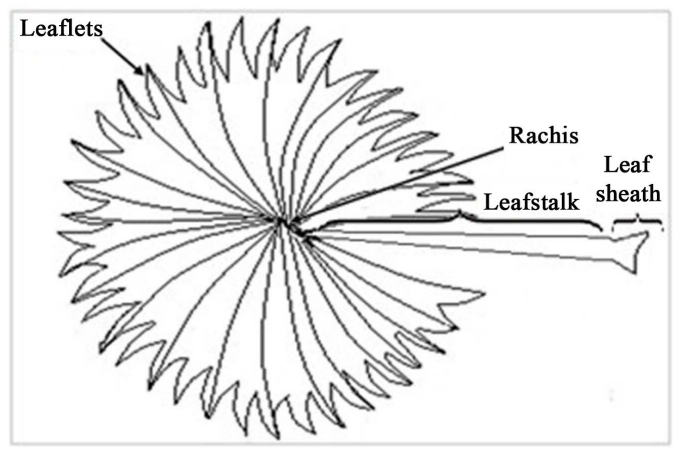

Figure 1. Different parts of leaf of palm tree.

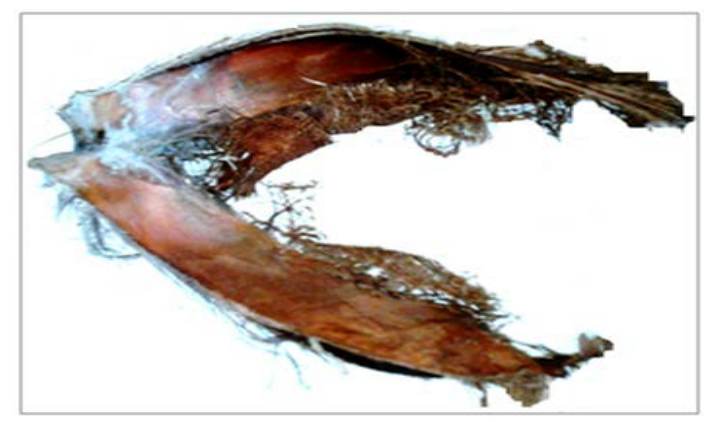

Figure 2. Leaf sheath of doum palm. 
The extraction of fiber from the leaf sheath was performed using a chemical process (soda treatment).

\section{B. Methods}

\section{1) Fibre extraction}

The extraction of vegetable fibers is to destroy the polygonal structure beam fiber to be identified. According to the literature, the extraction of vegetable fibers may be performed by a mechanical, biological, chemical or a combination of three methods [26]-[28].

Several studies have revealed how various conditions of treatments alkali concentrations, treatment temperatures and times during affect the properties of natural fibers [4] [29]. However, to the best of our knowledge, no data has been reported yet regarding the chemical treatment of these materials in particular the leaf sheath. Also, there are limited works reported concerning attempts to determine the main effect and the interaction between these three factors (soda concentration, temperature and duration of treatment) on it outcome to natural fiber physicochemical and mechanical properties performance. For that, several experiments were carried out to study the suitable conditions for extracting fibers from leaf sheath of Doum palm tree.

The fibers were extracted by means of a chemical treatment under pressure and agitation using a Datacolor AHIBA MSTRI. For this, we used the Tagauchi L18 design (Table 1). An experimental database has been elaborated by varying the doum palm extraction parameters.

The factor levels were chosen based on literature first and thereafter the preliminary tests. Indeed, in most of the references [13] [14] found that a temperature of $100^{\circ} \mathrm{C}$ is the most widely adopted for extraction of palm fiber. Then by the first trials it was found that the lower temperature below which the extraction is no longer possible to $80^{\circ} \mathrm{C}$ and the highest one above which we will have a hydrolysis of material was $120^{\circ} \mathrm{C}$. Regarding the concentration of sodium hydroxide, it began with a concentration of $0.25 \mathrm{~N}$ as the lowest concentration below which extraction is impossible and we stop at a concentration of $2 \mathrm{~N}$ because beyond which raw material will be damaged. As for the duration it has been found that duration less than 60 minutes is insufficient for fibers extraction while duration over 180 minutes will be destructive for the material.

In this database (18 tests), we used as input variables the temperature, the extraction time, and the soda concentration. The outputs are the fiber yield, the diameter, the density, the linear density and mechanical properties.

The leaf sheath is cut in rectangular slots which have length ranging from 10 to $12 \mathrm{~cm}$ (Figure 3). Subsequently, it is immersed in the following extraction bath:

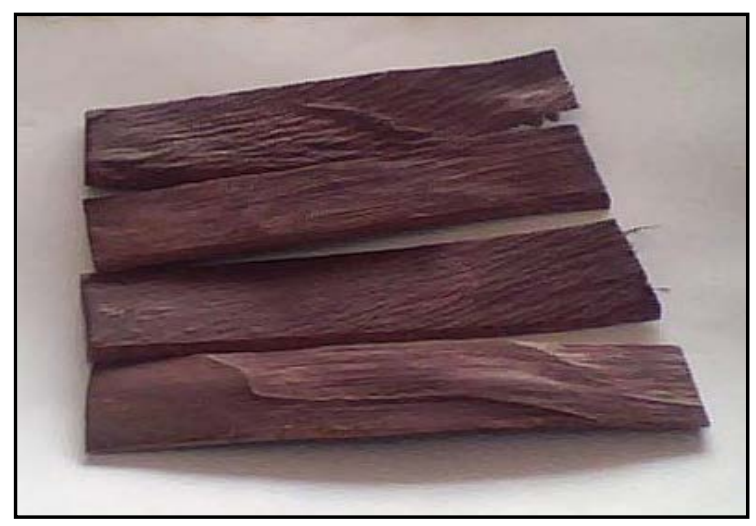

Figure 3. Leaf sheath cut in the form of rectangular slices.

\begin{tabular}{|c|c|c|c|c|c|c|}
\hline \multirow[b]{2}{*}{ Factors } & \multicolumn{6}{|c|}{ Levels } \\
\hline & 1 & 2 & 3 & 4 & 5 & 6 \\
\hline Concentration en soude (N) & 0.25 & 0.5 & 0.75 & 1 & 1.5 & 2 \\
\hline Temperature $\left({ }^{\circ} \mathrm{C}\right)$ & 80 & 100 & 120 & & & \\
\hline Time (mn) & 60 & 120 & 180 & & & \\
\hline
\end{tabular}


- $10 \mathrm{~g}$ of dry leaf sheath.

- Liquor ratio $=1 / 20$

- Temperature $\left(\mathrm{T}\left({ }^{\circ} \mathrm{C}\right)\right)$ ranges from $80^{\circ} \mathrm{C}$ to $120^{\circ} \mathrm{C}$.

- Duration (D (min)) of treatment ranges from 60 to $180 \mathrm{~min}$.

- Sodium hydroxide concentration (C (N)) ranges from $0.25 \mathrm{~N}$ to $2 \mathrm{~N}$.

After treating the leaf sheath with sodium hydroxide, it is rinsed with water several times and the obtained bundles of fibers are dried to the ambient air for $48 \mathrm{~h}$. After drying, the fibers are bonded one to the other which has led us to combing with a comb to be identified.

\section{2) Morphological properties}

The technical palm fibers obtained are characterized by means of physical and mechanical analysis.

The specimens were observed using a Scanning Electron Microscope (SEM) to characterize the morphology of treated and untreated fibers.

\section{3) Physical properties}

The Measurement of linear density (title) of palm fibers is described according to the French standards NF G 07-007 (1983) [10]. The test was carried out on a batch of conditioned fibers to a normal atmosphere (relative humidity: $65 \% \pm 4 \%$, temperature: $20^{\circ} \mathrm{C} \pm 2{ }^{\circ} \mathrm{C}$ ).

The density of the palm fibers was determined by the method relating to the French standards NF T20-053 while using the carbon tetrachloride $\left(\mathrm{CCl}_{4}\right)$ as reference solution $(\mathrm{d}=1.595)$.

The average apparent diameter was measured with the profile projector according to the French standards NF G 07.004. The test is carried out on 100 fibers chosen at random.

\section{4) Mechanical properties: Strength and elongation at break}

The tensile test is carried out on a batch of 50 fibers according to NF G07-002 relating to the determination of the strength and elongation at break under tensile stress. The length between clamps is taken equal to $25 \mathrm{~mm}$. These tests were conducted on a LLOYD dynamometer with a constant speed equal to $20 \mathrm{~mm} / \mathrm{min}$ and a measurement cell of $50 \mathrm{~N}$.

\section{5) Yield measurement}

Yield of fibers (R\%) is measured by the percentage of the ratio between the final mass of the fibers after chemical extraction process (Mf) and that of the leaf sheath of Doum palm tree before chemical extraction process (Mi).

The measurement of these two weights is performed using the gravimetric method in accordance with standard NF G 08-001. The material is placed in a special oven equipped with a ventilator and a thermostat. Dehydration by heating at $105^{\circ} \mathrm{C}$ is carried out for at least 3 hours until a dry or almost dry constant weight $(\mathrm{Mf})$.

Desiccation is finished when two successive weightings made at 15 minute intervals give a less than $0.05 \%$ of the mass of the sample difference. We proceed in the same way to calculate the initial and final mass to obtain the fiber yield.

$$
\mathbf{R}(\%)=\frac{M f}{M i} \times 100
$$

\section{6) Fourier transform infrared spectroscopy}

Infrared spectra of raw and surface treated natural fibers were collected with a Perkin-Elmer FT-IR spectrometer Frontier. All the FTIR spectra were registered with Spectrum Software Suite on a PC computer connected to the spectrometer and then saved for further manipulation and processing. Spectra were recorded over the range $4000-650 \mathrm{~cm}^{-1}$, with a resolution of $4 \mathrm{~cm}^{-1}$ and 32 accumulations.

\section{Results and Discussions}

\section{A. Morphological and physical properties}

The characterization of fiber morphology is important since its influence on other processing methods of the fibers and the quality of products from it.

All fibers have a common structure, but their physical properties can vary in a substantial way depending on the method and conditions carried out for extraction.

Figure 4(a) and Figure 5(a) represent longitudinal views of the palm fibers studied. These figures show that this technical fiber have a cylindrical shape. Their structure is similar to a natural composite composed of ultimate fiber bundles of cellulose, thus forming the fibrous reinforcement, linked together by gummy and waxy 


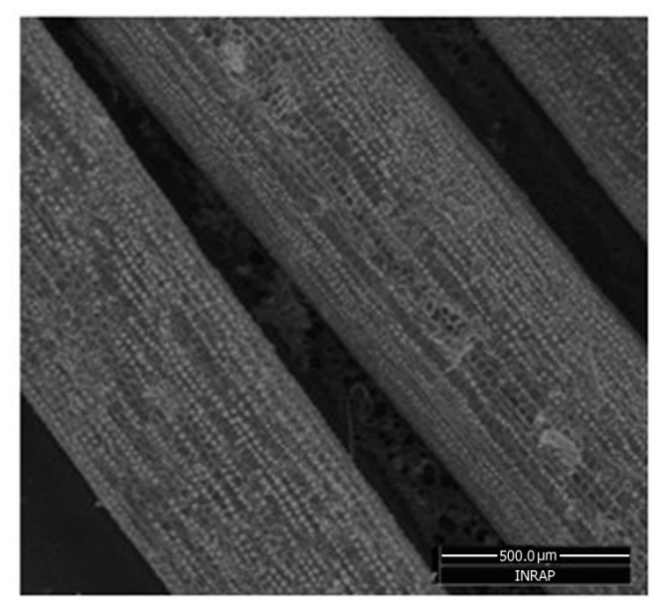

(a)

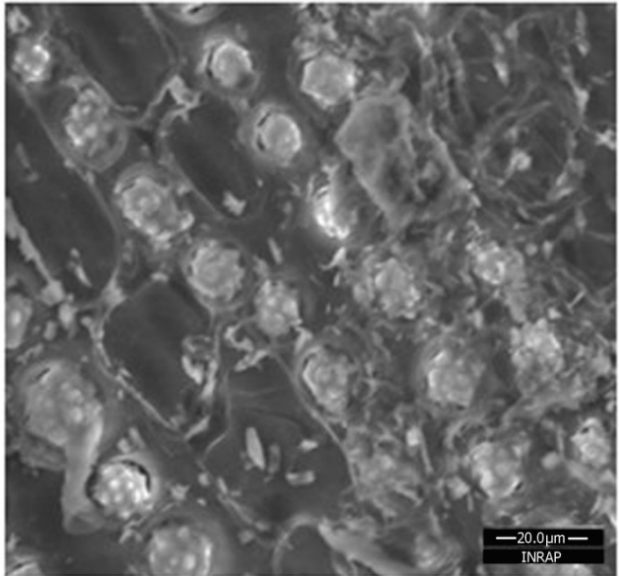

(b)

Figure 4. SEM micrographics of untreated palm fibers.

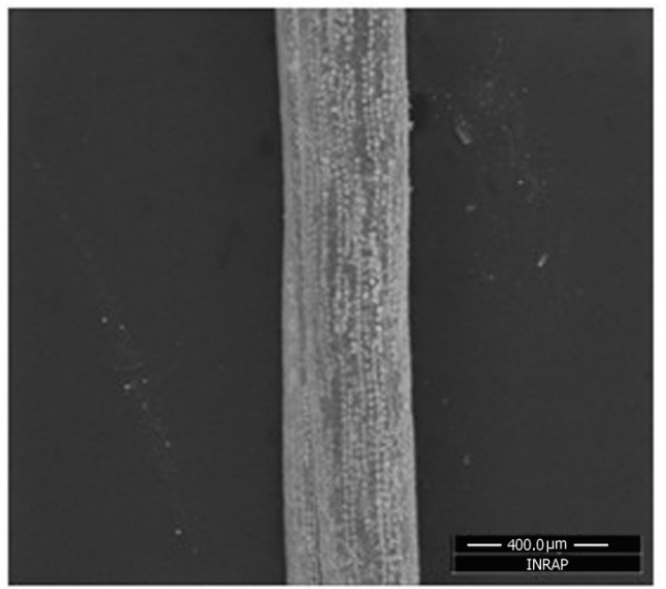

(a)

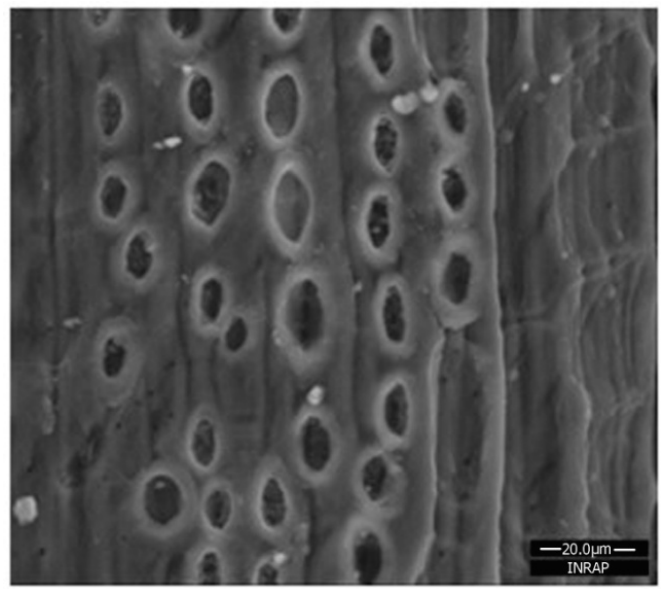

(b)

Figure 5. SEM micrographics of palm fibers obtained by chemical process Fibers.

substances, constituting the matrix.

As shown in Figure 4(b), the untreated fibers present on their surface woody and gummy substance. After soda treatment, SEM micrographics show (Figure 5(b)) an improvement in surface morphology. Then using soda treatment cleans the fiber surface of a large amount of impurities (gummy and waxy substances) and causes fibrillation. This is approved by the appearance of pores evenly distributed on the surface of the fibers after alkali treatment as shown in Figure 5(b).

The chemical process of extraction using sodium hydroxide allows the separation of fibers. In fact, the important modification done by alkaline treatment is the disruption of hydrogen bonding in the network structure, thereby increasing surface roughness. This treatment removes a certain amount of lignin, wax and oils covering the external surface of the fiber cell wall, depolymerizes cellulose and exposes the short length crystallites. Addition of aqueous sodium hydroxide $(\mathrm{NaOH})$ to natural fiber promotes the ionization of the hydroxyl group to the alkoxide. The following reaction takes place as a result of alkali treatment [18] [20]:

$$
\text { Fiber }-\mathrm{OH}+\mathrm{NaOH} \rightarrow \text { Fiber }-\mathrm{O}-\mathrm{Na}+\mathrm{H}_{2} \mathrm{O}
$$

The standard definition of mercerization as proposed by ASTM D1965 is: the process of subjecting a vegetable fiber to an interaction with a fairly concentrated aqueous solution of strong base, to produce great swelling with resultant changes in the fine structure, dimension, morphology and mechanical properties.

The type of alkali and its concentration will influence the degree of swelling, and hence the degree of cellu- 
lose structure changes. It has been reported that $\mathrm{Na}^{+}$has got a favorable diameter, able to widen the smallest pores between the lattice planes and penetrate into them. Consequently, sodium hydroxide $(\mathrm{NaOH})$ treatment results in a higher amount of swelling. This leads to the formation of new Na-cellulose-I lattice, a lattice with relatively large distances between the cellulose molecules, and these spaces are filled with $\mathrm{H}_{2} \mathrm{O}$ molecules. In this structure, the OH-groups of the cellulose are converted into O-Na-groups, expanding the dimensions of molecules. Subsequent rinsing with water will remove the linked Na-ions and convert the cellulose to a new crystalline structure. Mercerization was found to change fiber surface topography [18]-[20].

Thus, alkaline processing directly influences the cellulosic fibril, the degree of polymerization and the extraction of lignin and hemicellulosic compounds [20].

The fiber diameter was reported to be decreased with increased concentration of sodium hydroxide concentration [18].

To better visualize the effect of extraction conditions on the fiber fineness of Doum plam, contour plots were drawn. The evolution of different properties depending on the treatment time and concentration are given for a temperature of $100^{\circ} \mathrm{C}$.

The density of treated palm fibers was found more important than those untreated. The untreated palm fibers present a density equal to 0.47 , however The fibers obtained by chemical process present a density which ranges from 0.5 to 0.99 . As shown in the density contour plot (Figure 6), fiber extracted at high concentration and for longer times presented a higher density. The increase of doum palm fibers' density after chemical treatment could be attributed to the influence of alkaline treatment on the morphological structure of fibers. It increases the amount of cellulose exposed on the fiber surface [21]. Then the density become close to these of cellulose which is 1.5. Indeed, this treatment eliminates micro voids existing in the fiber and hence the volume decrease and density increase. This is a similar behavior of the sisal and the DPF fibers (Al-Khanbashi et al. 2005) [11], (Kuruvilla Josef et al. 1999) [12].

This density is close to that obtained for the date palm fibers (density varies from 0.51 to 1.08 ) [2]. This low density compared to other natural fibers (plant and animal) as well as synthetic fibers is an advantage for these fibers to find their use in composite materials in which the characteristic lightness is too important.

As shown in diameter contour plot (Figure 7) the diameter decrease when increasing the extraction conditions. This decrease in diameter is due to the soda treatment which has eliminated the gummy and waxy substances deposited on the fiber surface and cleaned them which confirm results shown by the SEM figures. Moreover,

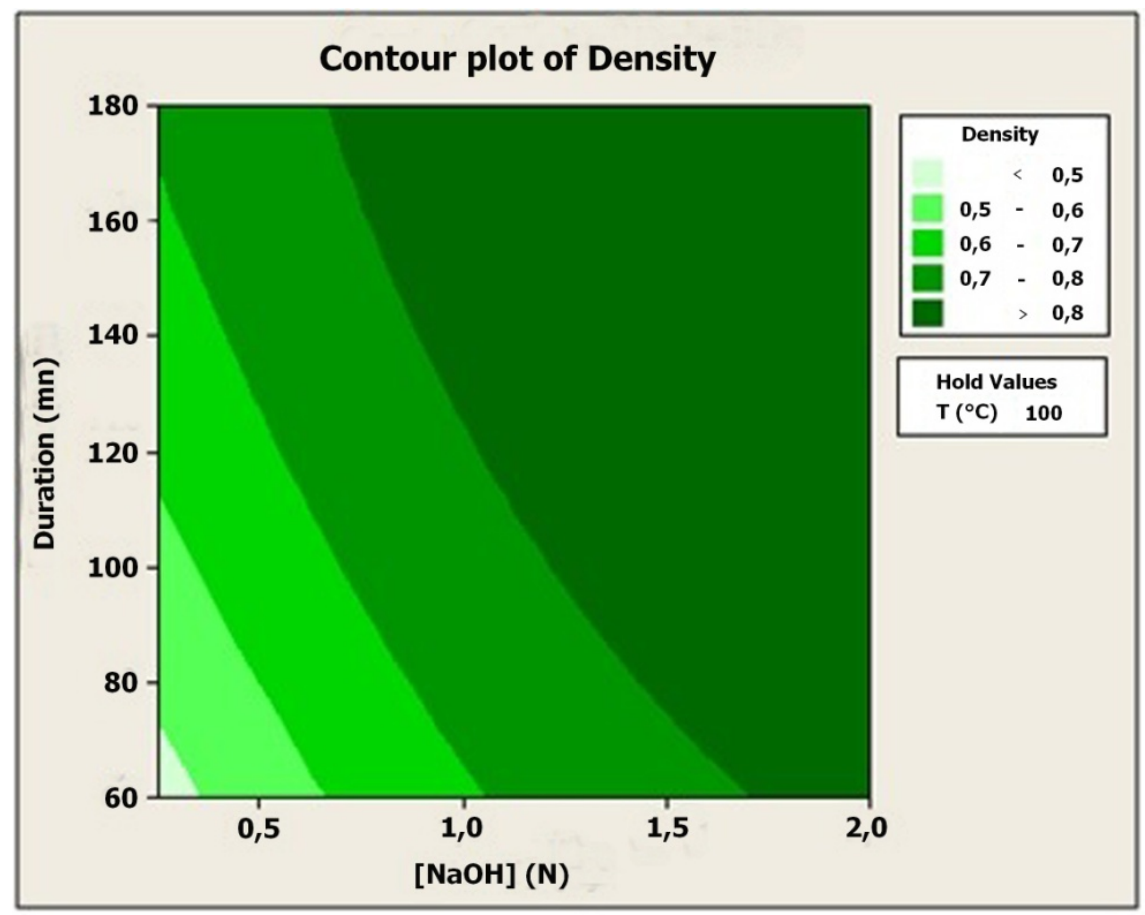

Figure 6. Contour plot of density; $\mathrm{T}=100^{\circ} \mathrm{C}$. 


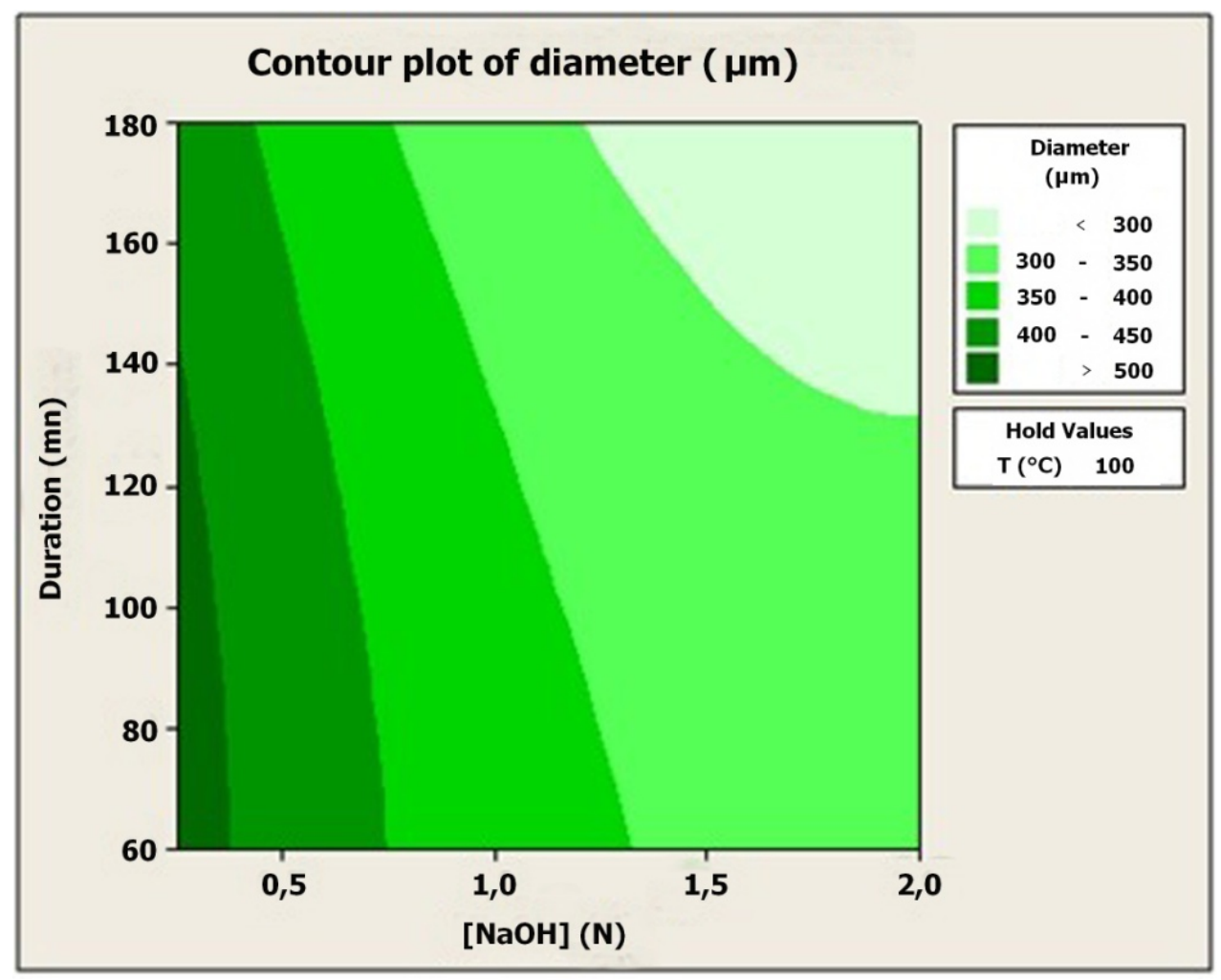

Figure 7. Contour plot of diameter $(\mu \mathrm{m}) ; \mathrm{T}=100^{\circ} \mathrm{C}$.

fibers extracted at $120^{\circ} \mathrm{C}$ for 2 hours inside [NaOH] solution of $2 \mathrm{~N}$, were observed to be thin $(280.35 \mu \mathrm{m})$. However, thick fibers are obtained by proceeding with the minimum conditions of treatment (temperature, concentration of caustic soda and duration of treatment) which also shows the influence of the extraction parameters on the properties of treated fibers. Also, the untreated fibers present a diameter about $689 \mu \mathrm{m}$. Then, in order to obtain a fine structure, extraction conditions need to be cruel. In fact, Treatment duration, soda concentration and temperature favor the separation of doum palm fibers and their cleanings while removing impurities and gummy materials which held the fibers in bundles such as pectin, lignin, hemicellulose, wax, and fat materials.

In addition to that, as shown in linear density contour plot (Figure 8), the linear density revealed the same behavior with diameter against hydroxide treatment. In fact, the untreated fibers present a linear density of 94.27 Tex. However the linear density of treated fibers ranges from 91.04 to 40.1 Tex. This reduce of mass per unit of length could be attributed to the removal of waxy and gummy materials present on the surface of fibers and between the ultimate fibers. The lower linear density was obtained in the combination $\left(120^{\circ} \mathrm{C}, 120 \mathrm{mn}\right.$ and $\left.2 \mathrm{~N}\right)$ which confirms result obtained of diameter.

This reducing in fibers fineness (diameter and linear density) could be proved by the results shown in the yield extraction. Bye the way, as revealed in yield contour plot (Figure 9), the yield decrease when increasing extraction conditions. The higher extraction yield is obtained while proceeding in the minimum condition of treatment which confirm the important fineness of fibers resulted in this case (diameter $=680.35 \mu \mathrm{m}$; linear density $=91.04$ Tex). Therefore, in this condition, the alkalization was not effective to remove foreign substances bundling fibers. When temperature, soda concentration and duration of treatment increase, the elimination of non cellulosic components becomes faster and more important, then yield decrease and consequently fineness.

The diameter of controlled fibers is morphologically similar to other palm fibers. Indeed, the surface date palm fibers have a diameter ranging between $100 \mu \mathrm{m}$ and $1000 \mu \mathrm{m}$ (Alawar, A. et al., 2009) [13].

Also, their means linear densities are higher than those of conventional fibers such as cotton fibers. But they are close to their obtained by F. Zbidi [14] for the case of doum palm fibers obtained from the petiole (mean linear density $=45.67 \mathrm{Tex}$ ). 


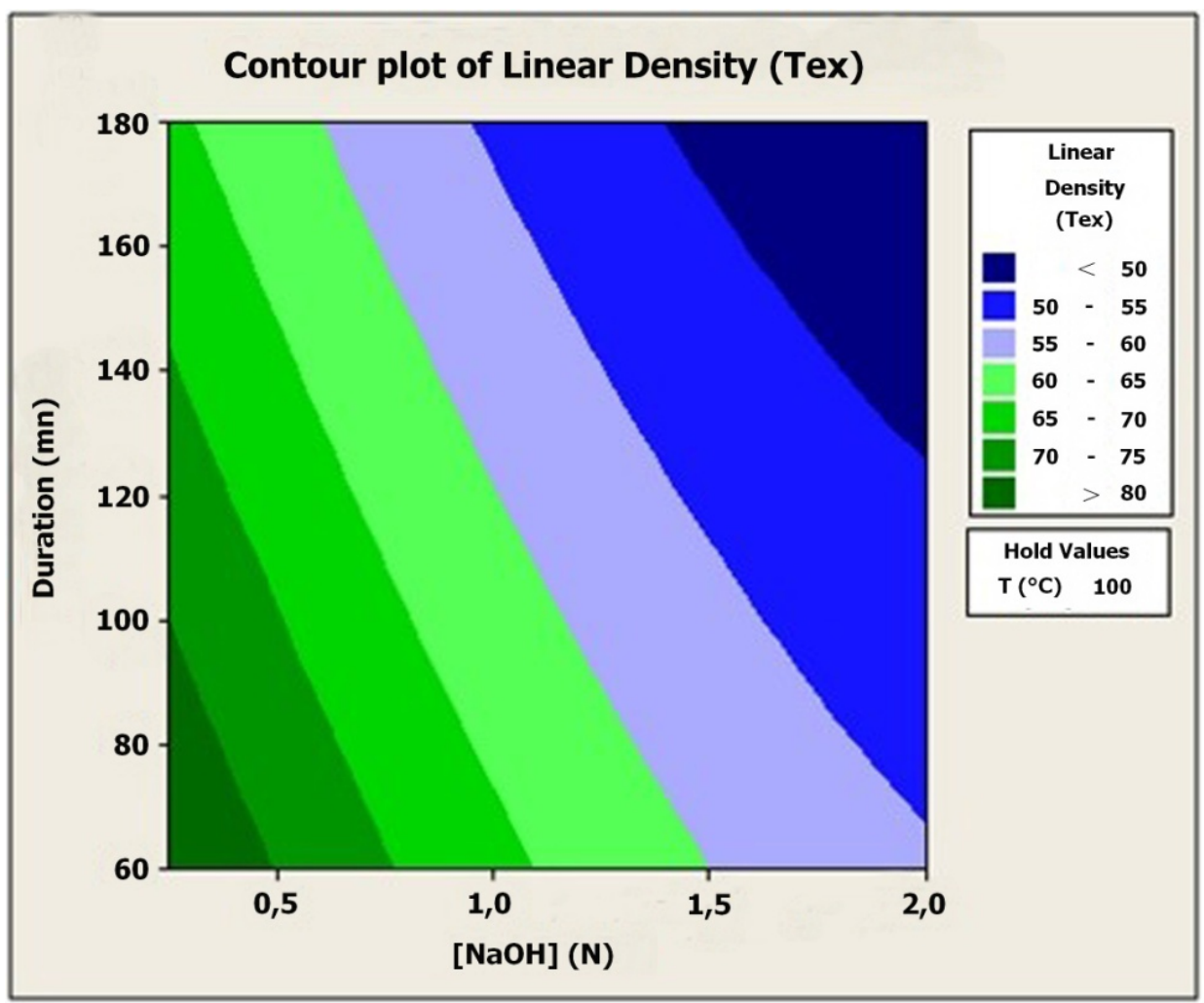

Figure 8. Contour plot of linear density (Tex); $\mathrm{T}=100^{\circ} \mathrm{C}$.

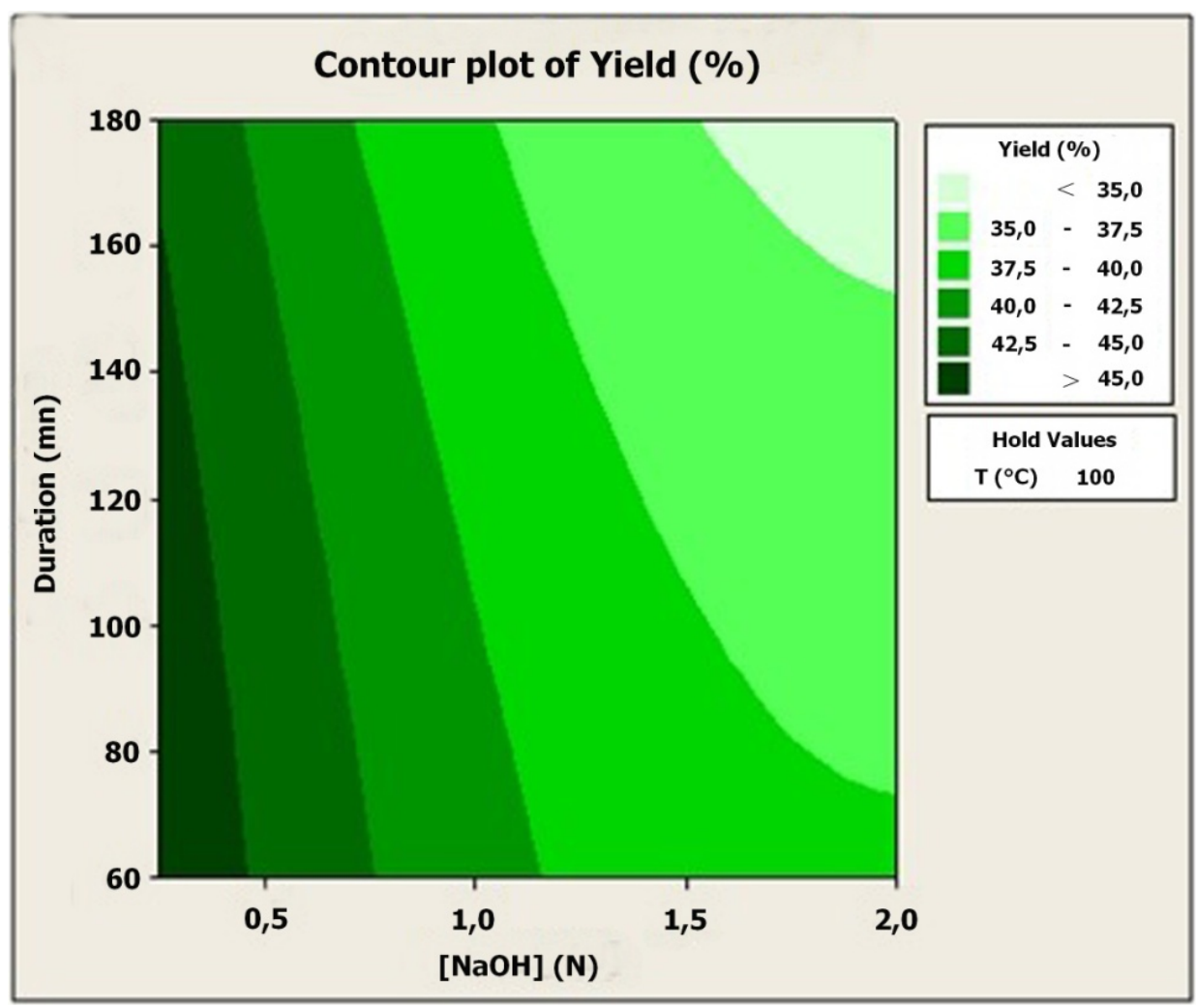

Figure 9. Contour plot of yield (\%). 


\section{B. Mechanical properties}

The mechanical properties of textile fibers are very interesting properties. However, they define in the first hand the behavior of fibers during different transformation processes and, in the other hand, the properties of the finished products made from these fibers. Depending on the significance of their characteristics, the lignocellulosic fibers such as those of the palm can be used in various applications.

For them within the textile structure, the tensile properties of fibers were sought in the majority of applications. The most important parameters to determine who can best describe this control are, therefore, the tensile strength and elongation, which is the corresponding elongation at break.

Table 2 present the mechanical properties of untreated and treated doum palm fibers.

The tenacity is defined by the ratio of the maximum load which can support a specimen and its linear density.

The materials' properties generally, depend, on their morphological structures and on their chemical compositions. The load of break and the elongation of break present a high coefficient of variation. This variation could be explained by the natural variability of the fibers studied, their specific morphological structure as well as the extraction method and extraction conditions.

As shown in tenacity and elongation contours plot (Figure 10 and Figure 11), the mechanical properties of fibers, the tenacity as well as the elongation to the break were varied after the alkaline treatment. In fact, the fibers obtained at a lower condition of treatment (temperature, $[\mathrm{NaOH}]$ and duration) have a mediocre tenacity while the removal of impurities from fibers was ineffective in this case. When increasing treatment conditions, the mechanical properties (tenacity and elongation) were improved. This can be explained by the fact that the soda treatment in this condition, favored arrangement of macromolecular chains of cellulose while eliminating

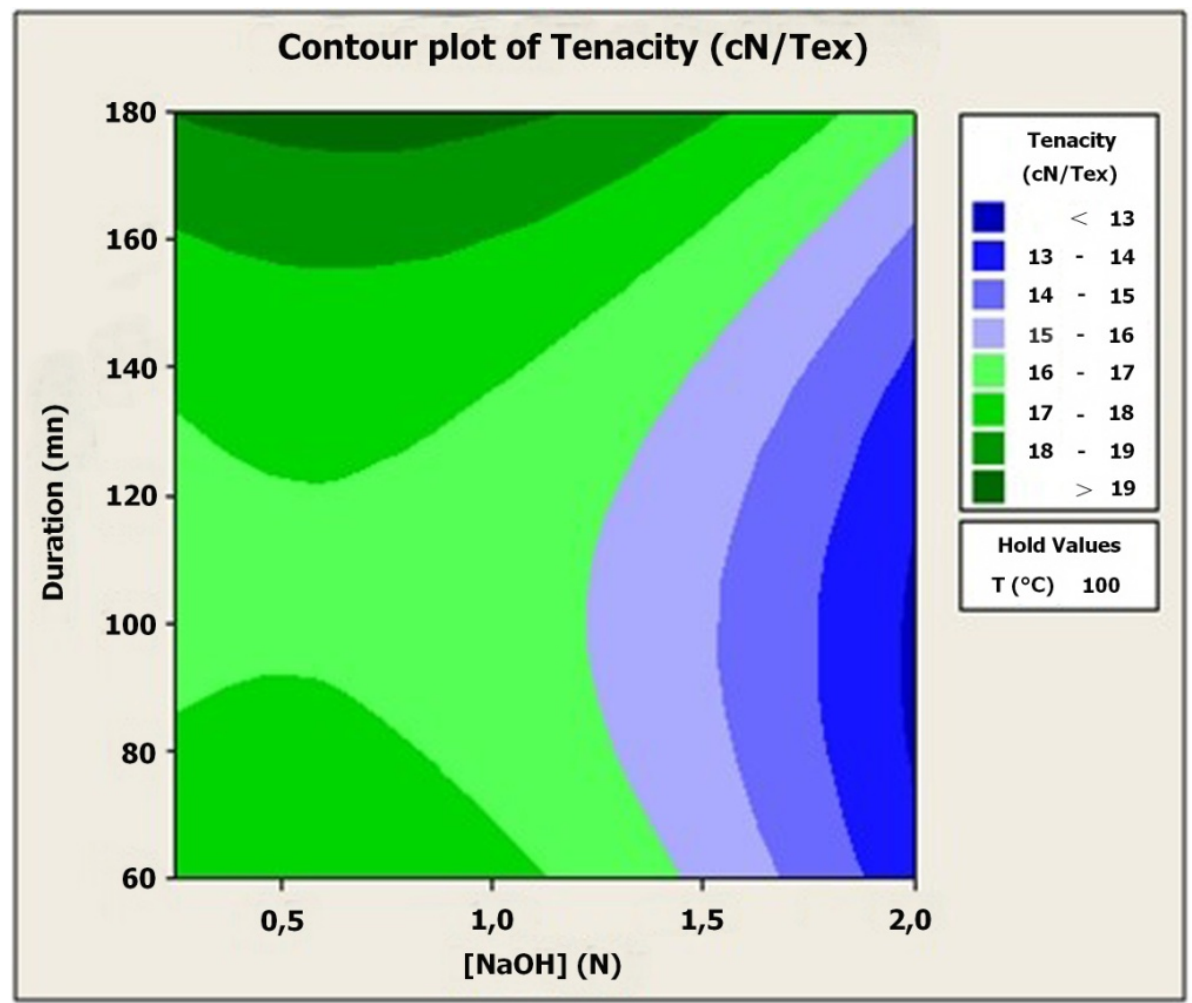

Figure 10. Contour plot of tenacity (cN/Tex); $\mathrm{T}=100^{\circ} \mathrm{C}$.

Table 2. Mechanical properties of doum palm fibers.

\begin{tabular}{ccccc}
\hline & $\mathrm{T}$ & $\mathrm{SD}$ & $\mathrm{E}$ & $\mathrm{SD}$ \\
\hline Untreated fibres & 13.2 & 2.16 & 11.43 & 1.15 \\
Treated fibres & $8.38-20.86$ & 3.03 & $10-14.18$ & 1.59 \\
\hline
\end{tabular}




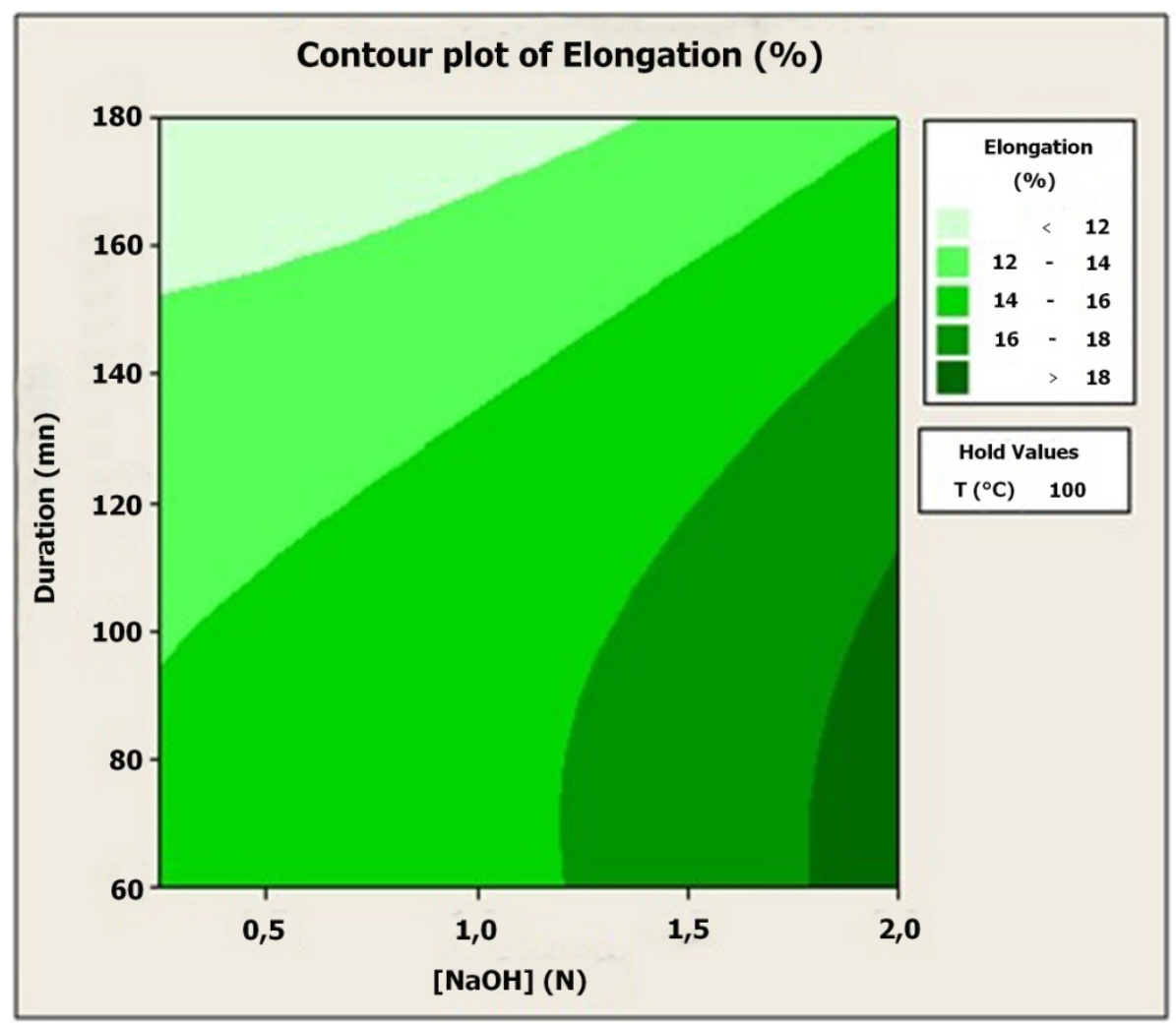

Figure 11. Contour plot of Elongation (\%); $\mathrm{T}=100^{\circ} \mathrm{C}$.

lignin and hemicelluloses deposited on the fiber. This increases the crystallinity of the fibers and subsequently their resistance. In fact, the effect of alkali on cellulose fiber is a swelling reaction, during which the natural crystalline structure of the cellulose relaxes. Native cellulose (i.e. cellulose as it occurs in nature) shows a monoclinic crystalline lattice of cellulose-I, which can be changed into different polymorphous forms through chemical or thermal treatments. Moreover, $\mathrm{NaOH}$ treatment can cause a lattice transformation from cellulose-I to a new crystalline structure, i.e. cellulose-II, which is thermodynamically more stable than cellulose-I [17]. In fact, the fibers tenacity achieved a threshold $(20.86 \mathrm{cN} / \mathrm{Tex})$ in the combination $\left(0.75 \mathrm{~N}, 100^{\circ} \mathrm{C}\right.$ and $\left.180 \mathrm{mn}\right)$. Increasing moreover the extraction conditions, the tenacity of fibers declines $(<13 \mathrm{cN} / \mathrm{Tex})$ as a result of destruction of cellulosic structure and greater impurity removal.

C. Comparison between Doum palm fibers and other vegetal fibers

In technical applications such as composites, the contribution of vegetal fibers is reflected in their low density and resistance.

The studied palm fibers have a lower density than those of vegetal fibers such as the flax, the cotton, the jute and the agave Americana $\mathrm{L}$ of which the densities are close to 1.5.

The palm fibers obtained by combined and chemical process have both a lower tenacity than the other vegetal fibers such as cotton, jute and agave Americana L. This property is close to that of flax fiber.

In order to show up the importance of fibers obtained from the Doum palm plant the tenacity/density ratio of various fibers was carried out (Table 3).

This table illustrates a comparison between Doum palm fibers (treated and untreated) and those commonly used in composites on the level of the $\tau / \mathrm{d}$ ratio; where $\tau$ is the tenacity (cN/Tex) and d is the density. The $\tau / \mathrm{d}$ ratio of the Doum palm fibers $\left(\mathrm{F}_{\mathrm{mc}}\right)$ is rather higher than that of Glass $\mathrm{E}$. This shows that the introduction of these fibers (Doum palm fibers) in polymer matrix can provide significant advantages compared to traditional fibers used in composites such as glass fiber.

\section{FT-IR Spectra}

FT-IR spectroscopy has been extensively used in cellulose research, since it presents a relatively easy method of obtaining direct information on chemical changes that occur during various chemical treatments. 
Table 3. Vegetable fibers compared to $\tau / \mathrm{d}$ ratio.

\begin{tabular}{|c|c|c|c|}
\hline Fiber & Tenacity (cN/tex) & Density $\left(\mathrm{g} / \mathrm{cm}^{3}\right)$ & Rapport ( $\tau / d)$ \\
\hline Cotton [15] & $26-44$ & $1.5-1.6$ & $17.33-27.5$ \\
\hline Jute [15] & $26-51$ & 1.3 & $20-39.23$ \\
\hline Flax [15] & $23-24$ & 1.5 & $15.33-16$ \\
\hline Agave Americana L [16] & 28.3 & 1.36 & 20.81 \\
\hline Glass E [15] & 75 & 2.5 & 30 \\
\hline Untreated fibres & 13.2 & 0.47 & 28.09 \\
\hline Treated fibres & 20.86 & 0.92 & 22.67 \\
\hline
\end{tabular}

FT-IR spectra of raw and treated fibers determined at $500-4000 \mathrm{~cm}^{-1}$ wave number are shown in Figure 12.

Similar absorption bands in the spectra are generally found in the fibers having the same chemical composition. The figure shows that the intensity of transmittance of the treated fibers is less than those untreated. This is could be explained by the fact that the structure become less opaque after chemical treatment. This transparence could be attributed to the elimination of certain amount of lignin, hemicelluloses and other fatty and gammy substances. The spectra of raw and treated fibers show a broad band observed at $3000-3500 \mathrm{~cm}^{-1}$ in the spectra indicating the presence of $\mathrm{OH}$ group. Another band was observed at $3000-2790 \mathrm{~cm}^{-1}$ indicating the stretching vibration of the groups $-\mathrm{CH}$ and $-\mathrm{CH}_{2}$ of cellulose and another band at $1411 \mathrm{~cm}^{-1}$, which also indicates the presence of $-\mathrm{CH}$ produced by a symmetrical deformation of lignin and alpha cellulose. The medium-intensity transmittance band at $1591 \mathrm{~cm}^{-1}$ is assigned to the $\mathrm{C}=\mathrm{O}$ stretching of carboxyl and acetyl groups in the hemicelluloses content of the fiber, which appeared as a strong peak in the case of untreated doum palm fibers and which indicated a higher hemicellulose content. But, it is noted that this absorption peak, was almost missing in the spectrum of the alkali treated fiber, indicating the elimination of hemicelluloses occurred by alkali treatment. The peak at $1542 \mathrm{~cm}^{-1}$ observed in raw fiber was missing in the treated samples. This was more likely attributed to the $>\mathrm{C}=\mathrm{O}$ group present in the lignin moiety as well as in other soluble polysaccharides, which was partially eliminated during alkaline treatment. Furthermore, the ratio of the intensities of the transmittance peaks at 3336 $\mathrm{cm}^{-1}(-\mathrm{OH})$ and $2932 \mathrm{~cm}^{-1}\left(>\mathrm{CH}_{2},>\mathrm{CH}^{-}\right)$for the raw (1.007) (1.008) and treated (0.93) (0.96) fibers indicated the presence of more $-\mathrm{OH}$ groups in the treated fiber than in the virgin sample. This was more likely due to the generation of new - $\mathrm{OH}$ groups on cellulose during alkaline treatment via the cleavage of phenolic ether links existing between cellulose and lignin moieties. The sharp peak at $1031 \mathrm{~cm}^{-1}$ has been attributed to C-O-C antisymmetric bridge stretching in cellulose and hemicelluloses. The small sharp band at $872 \mathrm{~cm}^{-1}$ in the spectra is attributed to $\beta$-glucosidic linkages between the sugar units in hemicelluloses and celluloses [23]-[25].

The analysis of the IR spectra of the untreated doum palm fiber showed characteristic features of lignin and hemicellulose components, which indicated that the fiber was lignocellulosic in nature. The IR analyses clarified the elimination of hemicellulose by alkali treatment, which results in the untreated fiber bundle broken down into smaller ones [22].

\section{E. Degree of control factors influence on the physical and mechanical properties}

In order to conclude on the importance of extraction conditions, a statistical analysis of the effect of temperature, soda concentration and duration of the treatment on the various properties was developed. Results of p-values are shown in Table 4.

From this table, the most influent parameter on the measured properties was soda concentration which affects mostly the majority of its (density, linear density, diameter, tenacity and yield).

\section{Conclusions}

The doum palm fiber is vegetable fiber which derives from the abundant leaf sheath of doum palm in Tunisia. In this study we have investigated the physical and mechanical properties of these fibers.

The SEM micrographics show the composite structure which presents these fibers, where the ultimate fibers are clumped together by gummy and waxy substances in one hand and on the other hand it shows the roughness fibers surface due to the alkaline treatment. 
Table 4. p-values meaning.

\begin{tabular}{ccccccc}
\hline & Density & $\begin{array}{c}\text { Linear density } \\
(\mathrm{Tex})\end{array}$ & $\begin{array}{c}\text { Diameter } \\
(\mu \mathrm{m})\end{array}$ & $\begin{array}{c}\text { Tenacity } \\
(\mathrm{cN} / \mathrm{Tex})\end{array}$ & $\begin{array}{c}\text { Elongation } \\
(\%)\end{array}$ & $\begin{array}{c}\text { Yield } \\
(\%)\end{array}$ \\
\hline$[\mathrm{NaOH}](\mathrm{N})$ & $* *$ & $* *$ & $* *$ & $* *$ & $*$ & $* *$ \\
$\mathrm{~T}\left({ }^{\circ} \mathrm{C}\right)$ & $*$ & $* *$ & $* *$ & $*$ & $*$ & $* *$ \\
$\mathrm{D}(\mathrm{mn})$ & $*$ & $* *$ & $* *$ & $*$ & $*$ & $* *$ \\
\hline
\end{tabular}

${ }^{*}$ : insignificant influence $(\mathrm{p}>0.05) ;{ }^{* *}$ : significant influence $(\mathrm{p}<0.05)$.

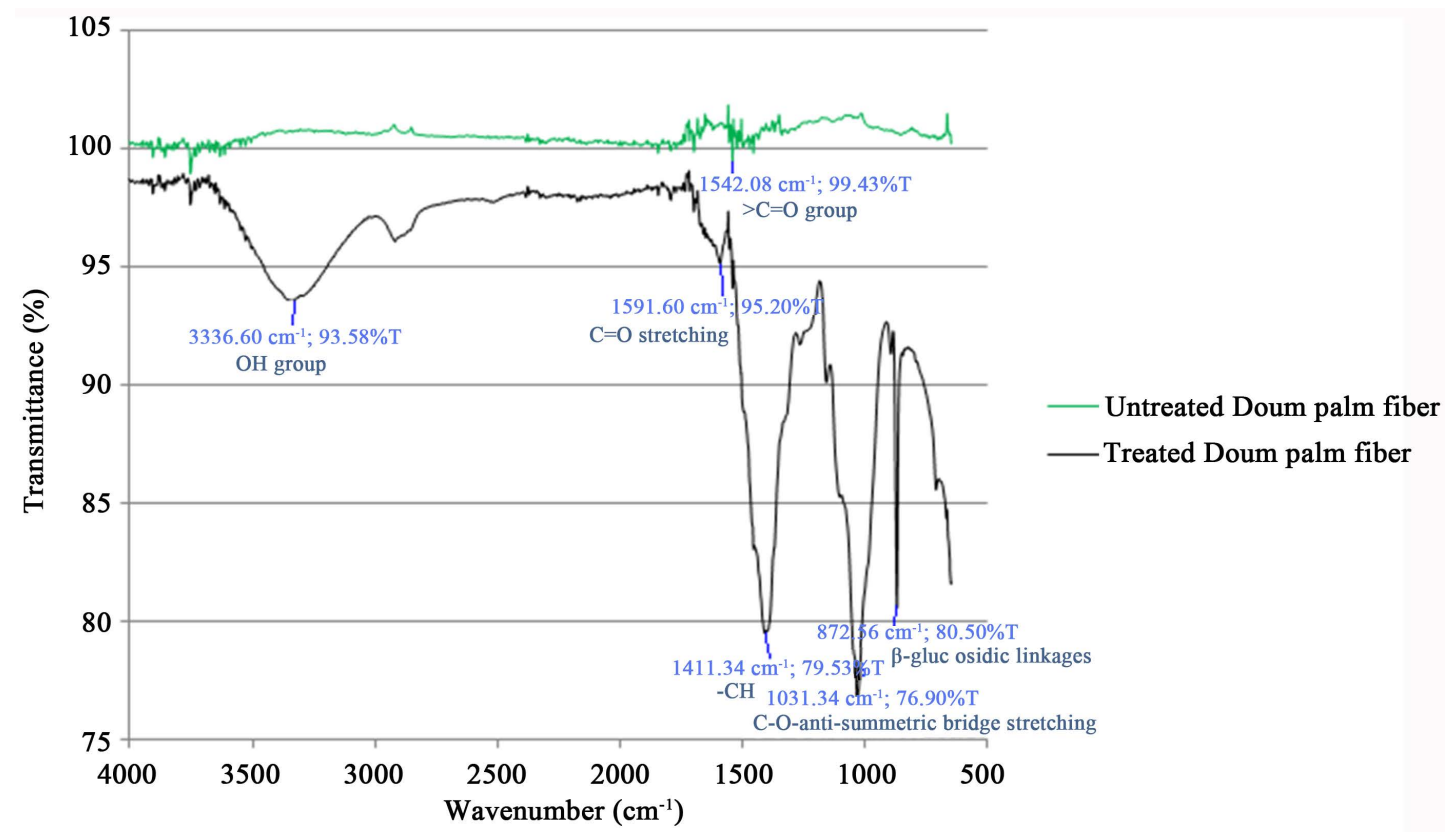

Figure 12. FT-IR spectra of treated (a) and untreated doum palm fiber (b).

Also, they have a low density compared to other fibers. Indeed, the density of these fibers does not exceed 1 which is a very important point for applications in composite materials or geotextiles.

The mechanical properties of these fibers were very interesting expressed by a high tenacity ( $>20 \mathrm{cN} / \mathrm{Tex}$ ) for the combination $\left(0.75 \mathrm{~N}, 100^{\circ} \mathrm{C}\right.$ and $\left.180 \mathrm{mn}\right)$.

The FTIR spectra reveal the lignocellulosic structure of these fibers and their modification after alkalization. This modification in structure is attributed to the increase of cellulose amount exposed on the fiber surface since a large amount of lignin and hemicellulose has been eliminated. Then this change increases the number of possible reaction sites (OH groups) when composites are reinforced.

In the end, we can notice the impossibility of spinning the fibers studied bellow because of their high linear density and diameter and rigid structure. This gross structure is expressed by the relatively high linear density (94.27 Tex-40.1 Tex).

\section{References}

[1] Srinivasa, C.V., Arifulla, A., Goutham, N., et al. (2010) Static Bending and Impact Behaviour of Areca Fibers Composites. Materials and Design, 32, 2469-2475.

[2] Rao, K.M.M. and Rao, K.M. (2007) Extraction and Tensile Properties of Natural Fibers: Vakka, Date and Bamboo. Composite Structures, 77, 288-295. http://dx.doi.org/10.1016/j.compstruct.2005.07.023

[3] Bledzki, A.K. and Gassan. J. (1999) Composites Reinforced with Cellulose Based Fibres. Progress in Polymer Science, 24, 221-274. http://dx.doi.org/10.1016/S0079-6700(98)00018-5

[4] Zbidi, F., Sghaier, S., Nejma, M.B. and Zidi, M. (2009) Influence of Alkaline and Enzymatic Treatments on the Properties of Doum Palm Fibers and Composites. Journal of Applied Sciences, 9, 366-371. 
http://dx.doi.org/10.3923/jas.2009.366.371

[5] Garkhail, S.K., Heijenrath, R.W.H. and Peijs, T. (2000) Mechanical Properties of Natural Fibre Reinforced Thermoplastics Based on Flax Fibres and Polypropylene. Applied Composite Materials, 7, 351. http://dx.doi.org/10.1023/A:1026590124038

[6] Annamalai, P.K., Singh, R.P. and Sarwade, B.D. (2005) Durability of Composites Prepared from Ethylene-Propylene Copolymer and Jute Fiber under Accelerated Aging and Biotic Environment. Materials Chemistry and Physics, 92, 458-469. http://dx.doi.org/10.1016/j.matchemphys.2005.01.027

[7] Aziz, S.H. and Ansel, M.P. (2004) The Effect of Alkalization and Fiber Alignment on the Mechanical and Thermal Properties of Kenaf and Hemp Bast Fiber Composites. Composites Science and Technology, 64, 1219-1230. http://dx.doi.org/10.1016/j.compscitech.2003.10.001

[8] Haque, M., Haque, M., Islam, S. and Alic, E. (2009) Physico-Mechanical Properties of Chemically Treated Palm and Coir Fiber Reinforced Polypropylene Composites. Bioresource Technology, 100, 4903-4906. http://dx.doi.org/10.1016/j.biortech.2009.04.072

[9] Romain, T. (2008) Anatomie des palmiers (Arecaceae Bercht. \& J. Presl) et identification: Application à l'archéobotanique, Master de Systématique Evolution Paléontologie, université Pierre et Marie CURIE.

[10] NF, G., 07-007 (1983) Fibers Tests-Determination of Fibers Linear Density. AFNOR, Paris, 272.

[11] Al-Khanbashi, A., Al-Kaabi, K. and Hammami, A. (2005) Date Palm Fibres as Polymeric Matrix Reinforcement: Fibre Characterisation. Polymer Composites, 26, 486-497. http://dx.doi.org/10.1002/pc.20118

[12] Joseph, K., Tolêdo Filho, R.D., James, B., Thomas, S. and de Carvalho, L.H. (1999) A Review on Sisal Fibre Reinforced Polymer Composites. Revista Brasileira de Engenharia Agricola e Ambiontal, 3, 367-379.

[13] Alawar, A., Hamed, A.M. and Al-Kaabi, K. (2009) Characterization of Treated Date Palm Tree Fiber as Composite Reinforcement. Composites Part B: Engineering, 40, 601-606. http://dx.doi.org/10.1016/j.compositesb.2009.04.018

[14] Sghaier, S., Zbidi, F. and Zidi, M. (2009) Characterization of Doum Palm Fibres, after Chemical Modification. Textile Research Journal, 79, 1108-1114. http://dx.doi.org/10.1177/0040517508101623

[15] Ghali, L., Zidi, M. and Roudesli, S. (2006) Physical and Mechanical Characterization of Technical Esparto (Alfa) Fibers. Journal of Applied Science, 6, 2450-2455.

[16] Msahli, S. (2002) Etude du potentiel textile des fibres d'agave Americana L. Thèse présentée à l'université de Haute Alsace.

[17] Mwaikambo, L.Y. and Ansell, M.P. (2002) Chemical Modification of Hemp, Sisal, Jute, and Kapok Fibers by Alkalization. Journal of Applied Polymer Science, 84, 2222-2234. http://dx.doi.org/10.1002/app.10460

[18] Hashim, M.Y., Roslan, M.N., Amin, A.M., Zaidi, A.M.A. and Ariffin, S. (2012) Mercerization Treatment Parameter Effect on Natural Fiber Reinforced Polymer Matrix Composite: A Brief Review. World Academy of Science, Engineering and Technology, 6, 1382-1388.

[19] Sreenivasan, S., Bhama Iyer, P. and Krishna Iyer, K.R. (1996) Influence of Delignification and Alkali Treatment on the Fine Structure of Coir Fibres (Cocos Nucifera). Journal of Materials Science, 31, 721-726. http://dx.doi.org/10.1007/BF00367891

[20] Li, X., Tabil, L.G. and Panigrahi, S. (2007) Chemical Treatments of Natural Fiber for Use in Natural Fiber-Reinforced Composites: A Review. Journal of Polymers and the Environment, 15, 25-33. http://dx.doi.org/10.1007/s10924-006-0042-3

[21] Valadez-Gonzalez, A., Cervantes-Uc, J.M., Olayo, R. and Herrera-Franco, P.J. (1999) Effect of Fiber Surface Treatment on the Fiber-Matrix Bond Strength of Natural Fiber Reinforced Composites. Composites Part B: Engineering, 30, 309-320. http://dx.doi.org/10.1016/S1359-8368(98)00054-7

[22] Sana, R., Mounir, J. and Slah, M. (2014) Study of Structure and Properties of Tunisian Typha Leaf Fibers. International Journal of Engineering Research \& Technology (IJERT), 3.

[23] Jaouadi, M., M'sahli, S. and Sakli, F. (2009) Optimization and Characterization of Pulp Extracted from the Agave Americana L. Fibers. Textile Research Journal, 79, 110-120.

[24] Nelson, M.L. and O’Connor, R.T. (1964) Relation of Certain Infrared Bands to Cellulose Crystallinity and Crystal Lattice Type. Part II. A New Infrared Ratio for Estimation of Crystallinity in Cellulose I and II. Journal of Applied Polymer Science, 8, 1325-1341. http://dx.doi.org/10.1002/app.1964.070080323

[25] Adebajo, M.O. and Frost, R.L. (2004) Infrared and 13C MAS Nuclear Magnetic Resonance Spectroscopic Study of Acetylation of Cotton. Spectrochimica Acta, Part A: Molecular and Biomolecular Spectroscopy, 60, 449-453.

[26] de Andrade Silva, F., Chawla, N. and de Toledo Filho, R.D. (2008) Tensile Behavior of High Performance Natural (Sisal) Fibers. Composites Science and Technology, 68, 3438-3443. 
[27] De Rosa, I.M., Kenny, J.M., Puglia, D., Santulli, C. and Sarasini, F. (2010) Morphological, Thermal and Mechanical Characterization of Okra (Abelmoschus esculentus) Fibres as Potential Reinforcement in Polymer Composites. Composites Science and Technology, 70, 116-122. http://dx.doi.org/10.1016/j.compscitech.2009.09.013

[28] Eva, R. (2010) Extraction et étude des propriétés physiques et mécaniques des fibres d’eAlfa (Esparto grass) en vue d'applications textiles. Mastère présentée à Ecole Nationale Supérieure d’Ingénieurs Sud-Alsace (UHA).

[29] Gomes, A., Goda, K. and Ohgi, J. (2004) Effects of Alkali Treatment to Reinforcement on Tensile Properties of Curaua Fiber Green Composites. JSME International Journal Series A Solid Mechanics and Material Engineering, 47, 541-546. http://dx.doi.org/10.1299/jsmea.47.541 
Scientific Research Publishing (SCIRP) is one of the largest Open Access journal publishers. It is currently publishing more than 200 open access, online, peer-reviewed journals covering a wide range of academic disciplines. SCIRP serves the worldwide academic communities and contributes to the progress and application of science with its publication.

Other selected journals from SCIRP are listed as below. Submit your manuscript to us via either submit@scirp.org or Online Submission Portal.
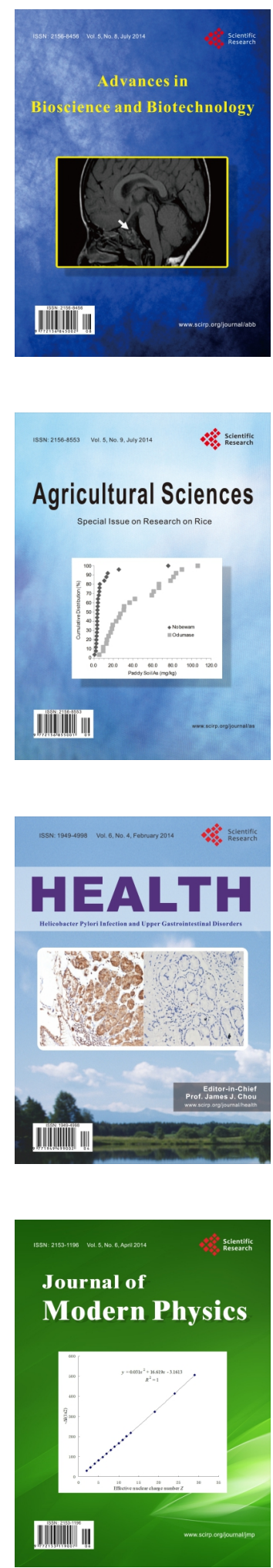
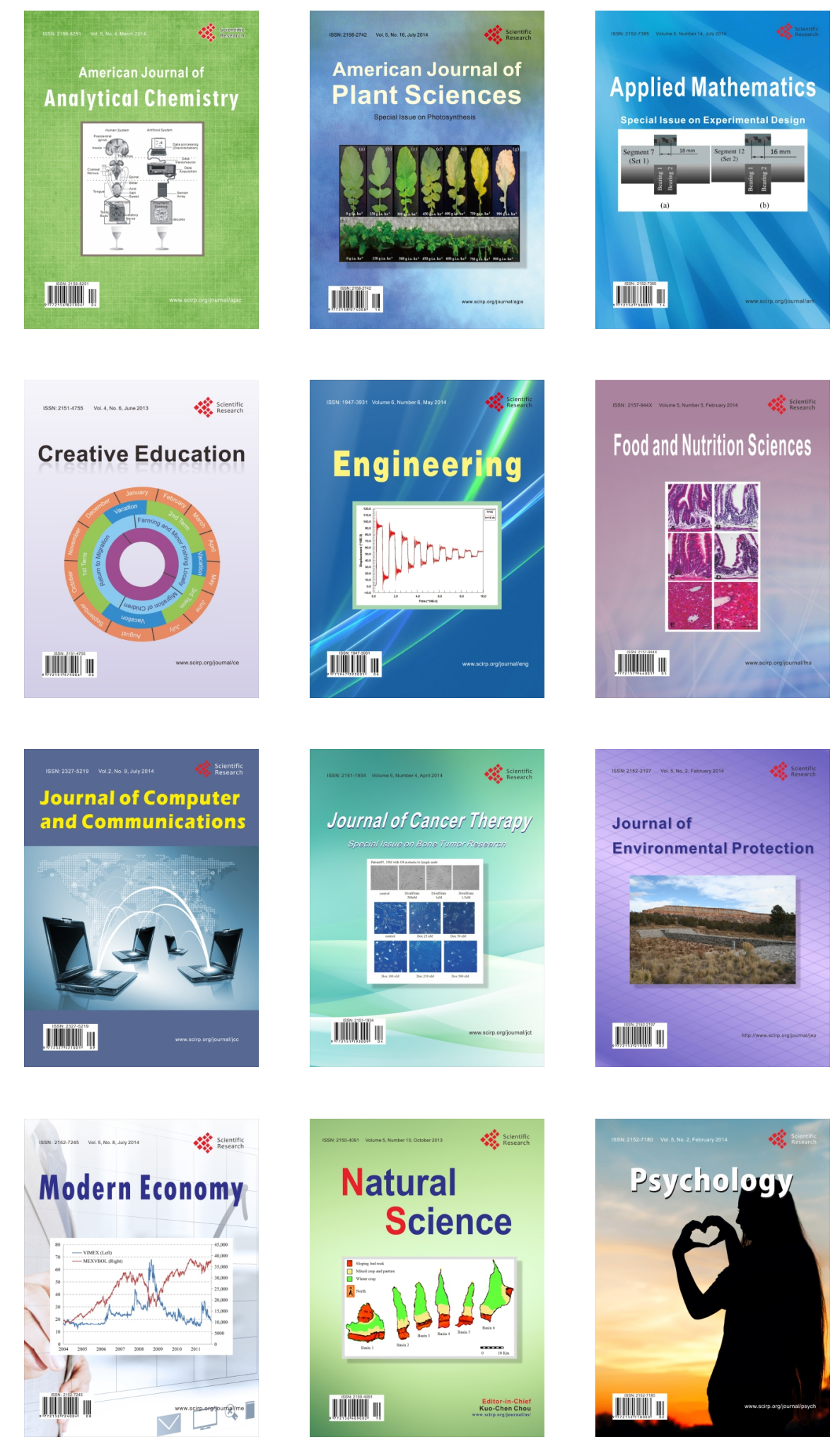